a quick oxygen-assisted climb between Camps III. and IV. by Mallory and Irvine, and there is a note by Mallory, written from Camp VI., telling Noel to be on the look-out with his cinema at 8 A.M., when he expected to be at the foot of the final pyramid. This suggests that Mallory expected to make, with oxygen, very rapid progress. On the other hand, Geoffrey Bruce and Odell both reported that they obtained little or no benefit from its use. The first such occasion was up to 23,000 feet, where its use could scarcely be expected to produce dramatic results in acclimatised climbers. The second occasion was at 27,000 feet, when Odell discarded oxygen and felt better without it. With the deference due from one who was not actually present, I suggest that the fault may have rested with the apparatus, and that the improvement in Odell's condition may have been due to the discarding of useless weight and partly possibly to the euphoria usually associated with anoxæmia. We know that the apparatus was cumbersome; inefficient, and leaky. We do not know to what extent Irvine's improvements and corrections, carried out without proper equipment and under the most difficult of conditions, may have broken down in use. The appearance of Mallory and Irvine, still below the final pyramid at 12.50, four and a half hours late, may have been due to a breakdown of the apparatus.

If, then, the oxygen school believes in the usefulness of oxygen for high climbers, whether acclimatised or not, and the no-oxygen school believes in its usefulness for the unacclimatised, a method of attack in conformity with both points of view appears at first sight to be obvious. It should be possible to eliminate the necessity for acclimatisation by using oxygen from a low level on the mountain and climbing it at alpine speed. But here two great problems present themselves. It is very difficult to construct an apparatus which will without waste deliver the required quantity of oxygen while the climber is eating and sleeping; and it is impossible at the moment to find an apparatus which can be trusted never to go wrong. The failure of his oxygen apparatus near the top of Everest would mean death to the unacclimatised mountaineer.

The other extreme view has also been presented, but never by anyone with experience of Himalayan climbing-the view that Everest should be attacked by a party prepared, if necessary, to spend a year upon the mountain. To rush a mountain is folly, unsound in theory and disastrous in practice. Siege tactics have been proved sound. But there must be moderation even in slowness. The weather of the great peaks allows only a limited time in which to make the ascent, and many months upon a mountain undermine the health of the climbing party. It is possible that before sufficient acclimatisation for an oxygenless assault on the summit of Everest has been attained, altitude deterioration may have set in. If by relying on oxygen for the last few thousand feet of Everest it is possible to reduce the time on the mountain and thus the danger of deterioration, the chances of a successful attempt will be increased. Whether this can be done will be determined by direct experiment in a steel decompression chamber.

The practical difficulties of oxygen are serious. The apparatus in use in 1924 was so heavy that, in the opinion of some, its weight outbalanced its advantages. Valves tend to freeze or leak, and complicated taps are difficult to work under trying conditions. Many improvements have been made in the last five years, but there is room for more. There should be produced a light, simple, and efficient apparatus, thoroughly tested in refrigerators and mid-tunnels and on the mountains of Europe. This task has been undertaken by a committee of the British Association. If such an apparatus can be designed it should, as soon as permission can be obtained, be placed in the hands of a young, well-drilled, and well-organised party. Such a party will, in my opinion, climb Everest. It will at any rate show us whether or not oxygen can be of service to the unacclimatised man.

\title{
The Principles of Evolution Revealed by Palæontology.*
}

\section{By Prof. Henry Fatrfield Osborn, For.Mem.R.S.}

$I^{\mathrm{N}}$ honour of Darwin our first thought is that natural selection is the sole survivor of the age-long theories and hypotheses clustering about evolution. Selection alone has stood the test of survival of the fittest, yet we must severely limit the powers of selection as Darwin imagined them in his earlier and more sanguine frame of mind, and glean the elements of truth pervading all the other hypotheses and theories. It is a striking fact that the zoologists, experimentalists, and geneticists who, a quarter century ago, were stoutly combating Wallace, Weismann, and other super selectionists, have, one after another, returned to the Darwinian fold and are now almost unani* Paper read before Section D (Zoology) of the British Association,
following Prof. E. B. Poulton's presidential address, entitled "A Century of Evolution ", on Sept. 24. This is the sixth of a series of papers by the author on the origin of species. mously teaching their students, as if it were a demonstrated fact, that evolution progresses by the survival of fortuitously adaptive mutations.

To the mind of the palæontologist these teachings are pure Darwinism camouflaged in new language. Bateson, founder of the genetic school, was the only one to confess frankly his utter failure to explain the origin of species; few have displayed similar courage.

When we consider the youthful zoology and the infantile palæontology of Darwin's time (1809-82), our admiration for his genius and marvellous powers of generalisation constantly increases. What would his generalisations have risen to with our present knowledge? He foresaw the promised land of palæontology, but did not live to enter it. The ratio of the 8767 vertebrate species known in

No. 3239, Vol. 128] 
his time to the 65,939 species known in 1925 , nearly 8 to 1 , is about the measure of the biological progress of the first century of evolution. The 'biochemical' adaptations underlying coloration, as well as the 'biophysical' adaptations controlling many of the animal instincts, are beyond the ken of the palæontologist who is bounded by his biomechanical fossils.

Far from marking any real progress toward the eternal question of the origin of co-ordinated mechanical adaptations, the experimental zoologist and geneticist are making little progress along the biochemical line. In order to ascertain the state of current observation and opinion on the mutational origin of species, sub-species, or adaptive mutations, as well as on the experimental results of biochemical, biophysical, and endocrine action, the following questionnaire (slightly modified) was sent out on July 17, 1931, to forty-one leading zoologists :

1. Do you know of a single concrete case of the origin of a species, of a sub-species, of an adaptive mutation of De Vries, or of a single adaptive character, arising suddenly by mutation or saltation either under natural or experimental conditions ?

2. Granted that permanent hereditary sports, mutations, and modifications of existing characters are being produced by biochemical and biophysical means, has a single adaptive character been produced by such means by experiment in your laboratories?

3. Granted that profound changes in colouring, in form, in somatic proportion, in the developmental acceleration or retardation of characters, may be produced by glandular action, is there sufficient evidence that Nature has ever proceeded in this way except in producing immunity and non-immunity ?

Up to the present time (Aug. 13) seventeen replies have been received. To Questions 1 and 2 the prevailing answers are negative as indicated by the reply "No". More or less positive or affirmative replies were also received to Question 1, but analysis of most of these replies indicates that the crucial element in Question 1 is evaded, namely, the origin of adaptive characters. No doubt certain mutations do survive ; many of them are recorded in the answers to the questionnaire; Crampton has discovered mutations in his monographic researches on the mollusc Partula; Chapman in the avian genus Buarremon; the short-legged Ancon sheep is a classic; certain biomechanical mutations in the pelagic Ciliata, such as the spiral shelf of Xystonella scandens observed by Kofoid, may be of sudden or mutational origin although this is not proved. The answers of seventeen zoologists to Question 2, namely, to adaptive biochemical origins by experiment, are uniformly negative; new and hereditarily permanent mutations may be aroused by more or less violent chemical or physical means, but not a single one is known to be adaptive. The answers to Question 3 are five negative and five affirmative; the negative squarely meeting the question, the positive reaffirming the granted postulate that endocrine secretions profoundly modify all existing characters and processes of development, but not a single case can be cited wherein a new bio- mechanical character has arisen through endocrine action.

In this struggle for existence of bygone theories and of new hypotheses, it seems that palæontology, with its world of new and wholly undreamt of evidence as to the origin of adaptive biomechanical characters, serves as the two-edged sword of bio$\operatorname{logy}$; it cuts hypotheses unfit to survive; it strengthens hypotheses fit to survive. It calls for conceptions of a new and synthetic physicochemical order to supplant outworn hypotheses dating back to Empedocles (600 в.c.). Palæontology disestablishes the entelechy hypothesis of Aristotle (300 B.c.) and of all his 'vitalistic' followers like Driesch and Bergson. It substitutes for Aristotle's ' internal perfecting tendency' the idea of adaptive reaction and interaction of internal with external energies which has been formulated (Osborn, 19121929) into a new tetraplastic principle of the 'four inseparable energetic factors of evolution ', namely : (1) physical environment, (2) ontogeny including habit, (3) living environment, the biota, (4) the germ plasm. The above energetic complex is subject to the non-energetic selection-survival of the fittest.

This tetraplastic principle which seeks to combine the elements of truth in preceding hypotheses and theories has, thus far, won no acceptance.

In causation of the origin of species and subspecies, palæontology unites with modern field zoology in firmly establishing the direct action of environment (Buffon, 1755-Wagner, 1870) on the germ plasm as a causative factor. It disestablishes the habit-inheritance law of Erasmus Darwin and of Lamarck (1790-1809) ; through auto-adaptation it establishes habit as a guiding principle in evolution, but not in the Lamarckian sense. Palæontology eliminates selection from the energetic complex; it establishes the non-energetic selection as a universal and outstanding guide and principle of progress from the beginning of time; it disestablishes the third and fourth principles of Charles Darwin (1859), namely, of the origin of adaptations through the survival of the fortuitously adaptive. It firmly establishes the inconspicuous adaptive origins of new characters first observed by Waagen (1869), which may be distinguished as $W$. mutations when compared with the fortuitous $D$. mutations of De Vries (1911). At least from biomechanical evolution it excludes entirely the fortuitous $D$. mutations of De Vries. It helps to disestablish the 'pangenesis' of Darwin and all similar theories of the somatic origin of adaptive characters; it accordingly disestablishes the " inheritance of acquired characters' and establishes the complementary principle of the " continuity of germ plasm ' of Weismann (1880). It disestablishes the super-selection theories of Weismann and other neo-Darwinians. In its earliest (1806), as well as its latest phases (1931), palæontology undermines the primitive idea of 'created evolution'; of recent years it tends to establish the wholly different idea of 'creative evolution', which may be provisionally termed aristogenesis. Finally, palæontology unites with systematic and experimental 
zoology in compelling us to concentrate research on the origin and co-ordination of bio-characters, in the lower animals and in man, as the outstanding problem of the second century of evolution.

Although primarily an original observer rather than a collator of other people's ideas, Darwin was more or less familiar with ten of the principles of 'biomechanical' adaptation which had been observed in the hard parts of animals from the time of the earliest Greek anatomists and philosophers. Throughout his frequent discussions of the biomechanical evolution of animals, are included the bony and muscular adaptations brought about through processes of (1) degeneration, (2) development, (3) compensation, (4) economy, (5) change of proportion, (6) co-adaptation, (7 and 8 ) acceleration or retardation, (9) self-adaptation, and (10) sports and discontinuities. One great principle remained to be established after his time, namely, (11) continuity of the germ plasm, in antithesis to all pangenetic hypotheses of the origin of hereditary characters. Note that all these ten pre-Darwin principles of adaptation relate not to the origins of organs, but to the modification of existing organs, as of the wings of the duck, the neck of the giraffe, the speed of the wolf. Darwin realised that the weak point in his theory was in the matter of origins; he could, and did, largely explain the survival value of organs once established, but was hard put to place a survival value on fortuitous variations.

Palæontology (1869-1931) has changed all this through a succession of discoveries revealing nine principles of adaptive biomechanical origin in the germ plasm. Thus, up to the present time, we have established through zoology and palæontology no less than twenty more or less distinct but invariably co-operative principles of bio-mechanical adaptation, as follows : of Waagen (1869), in which is involved (13) the ' trend 'or ' mutations richtung' of Neumayr (1875); (14-15) the ' acceleration and retardation' of Hyatt (1880), principles which Darwin could not clearly comprehend. In the year 1889, Osborn, at the time a convinced neo-Lamarckian, began his extremely intensive observations upon the origin and development of single adaptive characters, aided by unprecedented fossil material first in the primates and then in five independent divisions of the ungulates, wherein were revealed five previously undiscovered principles of biomechanical adaptation, namely: (16) germinal continuity versus discontinuity, and $W$. mutations ascending and descending; (17) germinal potentiality, as a basis of Lankester's principle of homogeny; (18) germinal predetermination, as distinguished from indeterminate origins ; (19) germinal rectigradations, as distinguished from fortuitous or chance origins. Finally, in the synthesis of the orthogenetic origin of new adaptive characters in all the mammals, including man, there was reached (20) the principle now provisionally termed aristogenesis for the want of a more appropriate word to express continuously creative adaptation.

A very important distinction is observed between rectigradations which are predetermined, and changes in proportion, as in the elongation of the neck of the giraffe, technically known as allometrons, which are not predetermined. Rectigradations are relatively rare, while allometrons, or changes of proportion in the teeth, skull, and limbs, are constantly in progress and make up a larger part of the definition of species. Similar rectigradations arise through community of descent. Similar allometrons are constantly arising in animals of dissimilar ascent.

Whereas the zoologist, comparative anatomist, and geneticist by the very nature of the evidence at their command, find difficulty in distinguishing

Modiftoation of Existing Organs, Ontogeny.

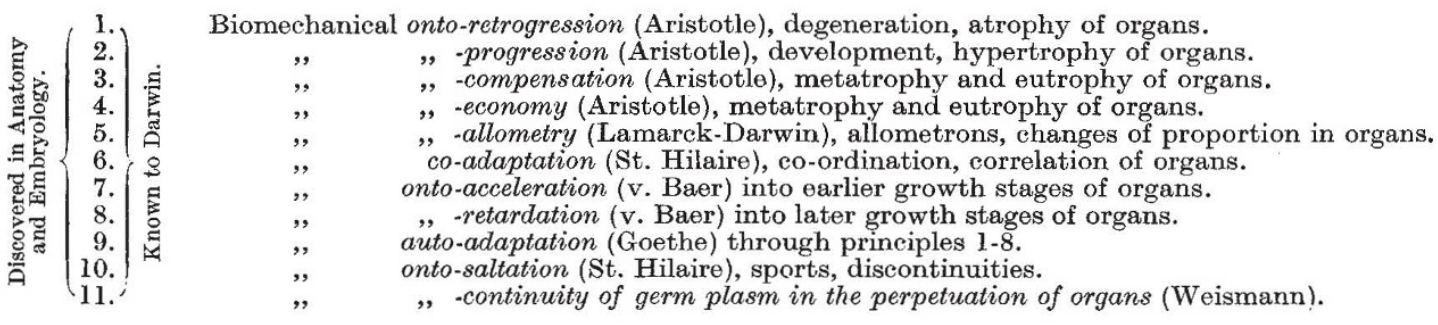

Origin of New Characters, Phylogeny.

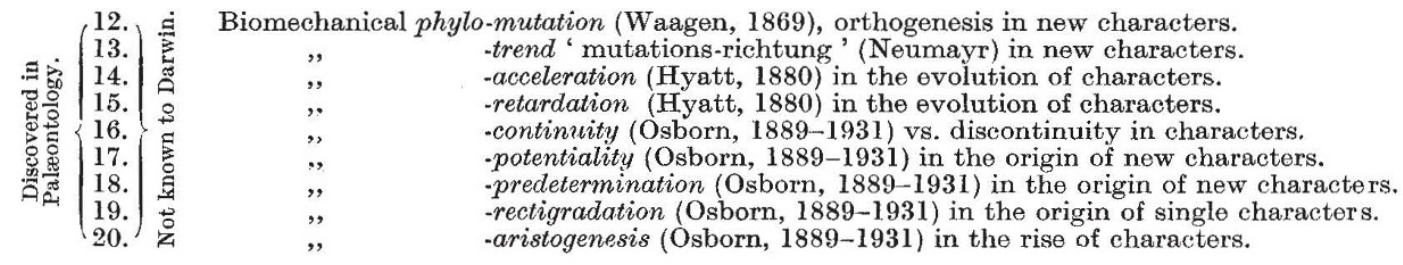

Of the nine principles of biomechanical origin discovered in phylogeny since Darwin's " Origin of Species" (1859), the first three were observed in fossil invertebrates, namely : (12) the $D$. mutations between the accidental, fortuitous, and temporary variations, fluctuations, and $D$. mutations, the palæontologist is absolutely sure of his footing as soon as he is enabled to observe the ascending

No. 3239, VoL. 128] 
geological mutations of animalmechanisms, whether invertebrate or vertebrate. He advances solely by inductive means, after the manner of Darwin. If he is not sure of the adaptive trend of a certain rectigradation in its feeble, incipient stage, he may observe it a hundired thousand or a million years later as the dominant and commanding character of the entire organism. As Weismann spoke of the immortality of the germ plasm, the palæontologist may speak of the secular immortality of thousands of characters which he is enabled to observe through the whole cycle from potentiality and predetermination in the germ plasm until, after æons of use and service, they may subside again into the mysterious germinal substance-mysterious because utterly inexplicable. The biomechanism of the titanothere and of the elephant is due to a complex of energetic factors which is entirely beyond our present comprehension.

The palæontologist concludes that the origin of species, so far as species are defined by various stages of biomechanical adaptation, has long ceased to be a problem; the manner by which sub-species, species, genera, families, and orders arise through divergence, acceleration, retardation, and rectigradation is also perfectly clear.

Selection acts incessantly, but it originates nothing, and it does not control either the origin of characters or their rate of evolution after they arise.

We can affirm that it is the essential living principle of biomechanical reaction which calls forth the adaptive biomechanical response, whether in ontogeny or in phylogeny.

While we know infinitely more about the principles of evolution than did Charles Darwin, and while we can demonstrate beyond refutation the prevailing twenty principles of biomechanical adaptation discovered in ontogeny and phylogeny, we are more at a loss than ever before to understand the causes of evolution. One after another the Buffonian, Lamarckian, Darwinian, Weismannian, and De Vriesian theories of causation have collapsed ; each, however, contains elements of truth. All that we can say at present is that Nature does not waste time or effort with chance or fortuity or experiment, but that she proceeds directly and creatively to her marvellous adaptive ends of biomechanism.

\section{Biology and Civilisation.}

$\mathrm{I}^{\mathrm{N}}$ $\mathrm{N}$ his Norman Lockyer lecture, delivered to the British Science Guild on Nov. 24, Dr. H. H. Dale dealt with the part which biology and biologists should play in modern civilisation. It is a commonplace that physical science and mechanical inventions have probably made greater changes in the conditions under which human beings live in the past hundred and fifty years than in the preceding twenty centuries. But this progress has led to many thinking of it in quantitative rather than qualitative terms, and forgetting that machinery was made for man and not man for machinery. It is possible that the imposing achievements of physical science have already, in the thoughts and interests of men at large, in our educational and public policy, as well as in technical and industrial development, overshadowed those of biology to an extent which threatens a one-sided development of science itself, and of the civilisation which we hope to see based on science.

Dr. Dale illustrated his argument by a reference to the physiological problems involved in flying. At the beginning of the War, physiologists were consulted on the subject of the difficulty of breathing at high altitudes. They sought permission to take small quantities of blood for investigation, and were asked by the authorities, what had blood to do with breathing? The question was not easy to answer with polite brevity, since British physiologists had, for several hundred years, been attempting to describe what blood has to do with breathing, and how it does it. To-day physiology has a proper place in the research organisation of the Royal Air Force; and with the development of machines capable of flying at several hundred miles an hour, has come the realisation that the reactions of the human organism to the stresses occasioned by these great speeds will play an important part in any further advances and may well prove to be the limiting factor.

Although biology and physical science have supplemented each other in our modern civilisation in such directions as the provision of pure water supplies and the disposal of sewage, in other directions there has been a lamentable divergence. The pollution of the atmosphere by smoke involves not only a direct waste of fuel and destruction of other materials, but also a very definite increase in ill-health from the absence of direct sunshine, which may be indicated indirectly by the stifled and stunted plant life in our northern cities and directly by the presence of rickets-the 'English disease' of German medical writings-among the growing children.

Dr. Dale described in some detail how our present knowledge of the etiology of this disease has come about. It is now certain that it is due to the absence from the body of a compound which is known as vitamin $\mathrm{D}$, which can be supplied either in the food or by exposure of the surface of the body to the sun's rays, or to some artificial source of light. The vitamin is formed from a compound known as ergosterol, under the action of the rays in the shorter wave-length region of the solar spectrum, either in the skin or in any food material containing its precursor. In practice, for its manufacture, an artificial source of light is used, which emits more of the shorter wave-lengths than reach the earth's surface from the sun. Recent work by Bourdillon and his colleagues in Great Britain, and by Windaus in Germany, has led to the preparation of a pure crystalline compound, of very great activity, which is probably the vitamin itself. In spite of our knowledge of the necessity of supplying 